\title{
Efficacy of phenytoin in the management of ventricular arrhythmias induced by hypokalaemia
}

\author{
Michael V. O'Reilly ${ }^{1}$ and Roderick T. MacDonald \\ From the Division of Cardiology, Wellesley Hospital, Toronto, Canada
}

Two cases of ventricular tachycardia and fibrillation induced by hypokalaemia refractory to, or aggravated by, lignocaine and procainamide are recorded. In both instances the administration of phenytoin was associated with an immediate and almost complete suppression of the arrhythmias. Hypokalaemia, procainamide, and quinidine prolong the $Q T$ interval and increase temporal dispersion of repolarization. Phenytoin does not increase the $Q T$ interval and does not aggravate the underlying disorder in hypokalaemia.

Ventricular arrhythmias induced by hypokalaemia are notorious and often resistant to therapy (Davidson and Surawicz, 1966; Guyer, 1964; Paulley, 1965; Pick, 1966; Sarma, I965; Scherf, Cohen, and Shafiiha, 1967; Swales, 1964). This phenomenon can be explained by the cellular effects of potassium and some of the more frequently used antiarrhythmic agents. Low potassium (Gettes and Surawicz, 1968), quinidine (Gettes, Surawicz, and Shiue, 1962), and procainamide (Pamintuan, Dreifus, and Watanabe, 1970) prolong the QT interval and thus the vulnerable phase of repolarization (Pick, 1964). Accordingly when both of these agents act synergistically the vulnerable phase is doubly prolonged and may encompass the time of occurrence of premature beats for which the antiarrhythmic agent is being exhibited (Pick, 1964). If the premature beats are not suppressed by the time the vulnerable phase is thus prolonged the likelihood of a repetitive mechanism occurring is greatly enhanced (Palmer, 1962; Watanabe, Dreifus, and Likoff, 1963; Vassalle, I97I). Phenytoin, which has a different mechanism of action at the cellular level and does not prolong the QT interval, would not be expected to have this effect (Palmer, 1962; Watanabe et al., 1963; Gettes, I97I). We recently managed two patients with arrhythmias induced by hypokalaemia where the beneficial effects of phenytoin as compared to the other agents were most striking.

\section{Case reports}

Case I A 6I-year-old alcoholic white woman preReceived 5 December 1972.

1 Present address: Department of Medical Physiology, Royal College of Surgeons of Ireland, St. Stephens Green, Dublin 2, Ireland. sented at the emergency room with a 24-hour history of seizures, hallucinations, and protracted vomiting after a prolonged alcoholic binge. She was conscious, disoriented, and irrational, with cold, clammy skin, a blood pressure of $60 \mathrm{mmHg}$ systolic by palpation, and a pulse of 100 per minute. After examination the patient was placed on a cardiac monitor and shortly thereafter ventricular fibrillation occurred. Direct current countershock reverted the mechanism to sinus rhythm with multiple ventricular premature beats. A roo mg bolus of lignocaine was given and a lignocaine infusion at $\mathrm{I-2} \mathrm{mg}$ a minute was initiated. The ventricular premature beats persisted with frequent runs of ventricular tachycardia, and after an additional $100 \mathrm{mg}$ of lignocaine the electrocardiogram showed broad, slurred QRS complexes with diffuse TU waves. During the ensuing 25 minutes there were repeated runs of ventricular tachycardia/fibrillation requiring repeated electrical defibrillation (Fig. I, strips I and 2). At this juncture the patient had received a total of $240 \mathrm{mg}$ of lignocaine intravenously without effect, and which indeed had been accompanied by a deterioration in her condition. Due to persistent episodes of ventricular tachycardia and fibrillation the lignocaine infusion was discontinued and phenytoin $250 \mathrm{mg}$ was given intravenously over 5 minutes. During administration of the phenytoin there was one further episode of ventricular flutter, corrected by direct current countershock (Fig. I, strip 2) (400 joules). Sinus rhythm was maintained thereafter for 15 minutes when a further episode of ventricular fibrillation occurred responding to a single countershock. An additional roo mg of phenytoin was administered intravenously stabilizing the rhythm without further ventricular premature beats or ventricular tachycardia (Fig. I, strip 3). At this time biochemical evaluation revealed $p \mathrm{H}$ of 7.5 and $\mathrm{K}^{+}$of only $2.2 \mathrm{mEq} / 1$. An infusion of $\mathrm{KCl}$ at $20 \mathrm{mEq}$ per hour was started, with an additional I $\mathrm{mEq} \mathrm{KCl}$ directly over 5 minutes some time after the first dose of phenytoin. In an effort to improve the haemodynamics and further stabilize the 


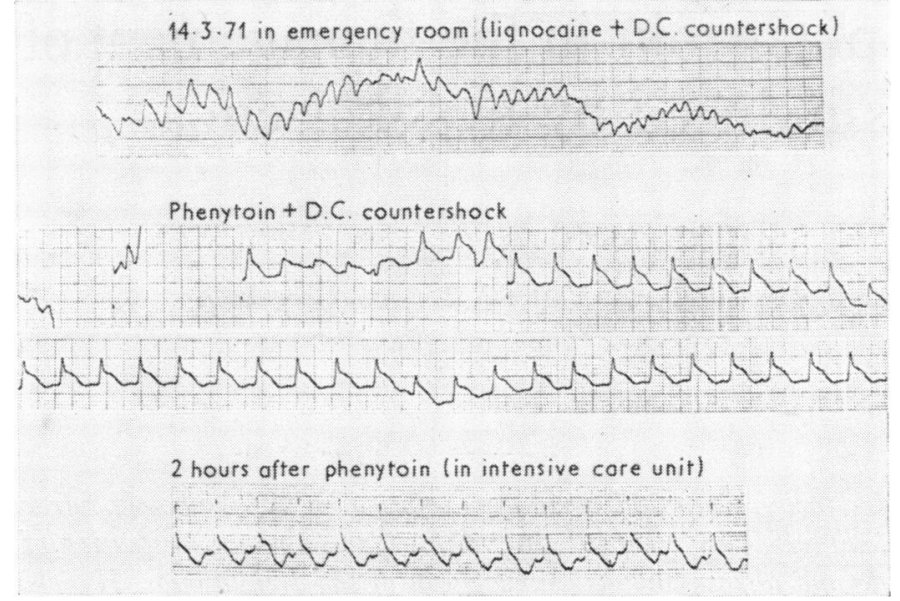

FIG. I Case I. Representative electrocardiogram strips - details in text.

myocardial electrical activity an isoprenaline infusion at $3 \mu \mathrm{g}$ per minute was initiated, and continued for 12 hours at I $\mu \mathrm{g}$ per minute with apparently good effect. $\mathrm{KCl}$ was also continued intravenously. A further $150 \mathrm{mg}$ of phenytoin was given intravenously 140 minutes after the initial arrest making a total of $500 \mathrm{mg}$ over 75 minutes. Cardiac rhythm remained stable and the QRS complex became narrower (Fig. I, strip 4). Phenytoin was continued for four days. During this time the patient's electrolytes and calcium slowly returned to normal, magnesium initially at $\mathrm{I} \cdot 18 \mathrm{mg} / 100 \mathrm{ml}$ was replaced with magnesium sulphate 50 per cent solution Io $\mathrm{ml}$ intramuscularly, twice a day. Urine output was good. The blood pressure rose to $120 / 70 \mathrm{mmHg}$, and though she remained drowsy with poor air exchange for some days she eventually recovered.

Case 2 A 60-year-old white woman presented in atrial fibrillation with a ventricular response of 1 I 5 per minute and ectopic ventricular contractions, congestive heart failure, and respiratory insufficiency. She was transferred to the medical intensive care unit. Digoxin $25 \mathrm{mg}$ intravenously, frusemide $120 \mathrm{mg}$ intravenously, and a slow infusion of aminophylline $(0.5 \mathrm{~g} / \mathrm{l}$.) was administered, with, in addition, lignocaine $\mathrm{I} \mathrm{mg}$ per minute for the ventricular premature beats. $\mathrm{Her} \mathrm{P}_{\mathrm{a}} \mathrm{O}_{2}$ remained low and she continued to deteriorate, requiring intubation and assisted ventilation. Initially the ventricular premature beats were suppressed by the lignocaine infusion, but after 36 hours resistant multifocal ventricular premature beats developed (Fig. 2, strip I). Procainamide $250 \mathrm{mg}$ intramuscularly and $100 \mathrm{mg}$ intravenous bolus of phenytoin were given with initially brief suppression of the arrhythmias. Procainamide was continued at 500 $\mathrm{mg}$ every 6 hours intramuscularly, without effect, the ventricular premature beats becoming more frequent. After a total of $1.25 \mathrm{~g}$ procainamide a brief episode of ventricular tachycardia occurred (Fig. 2, strip 2) aborted by lignocaine 100 $\mathrm{mg}$. The multifocal ventricular premature beats persisted with runs of ventricular tachycardia. Procainamide was discontinued, and as lignocaine $100 \mathrm{mg}$ was ineffective phenytoin $300 \mathrm{mg}$ was administered over 8 minutes. The rhythm stabilized without further episodes of ventricular tachycardia and only occasional ventricular premature beats. Biochemical evaluation later showed an arterial $p \mathrm{H}$ of $7.66, \mathrm{Po}_{2} 6 \mathrm{I}$ $\mathrm{mmHg}$ (on $60 \%$ oxygen via ventilator), and a potassium $2.6 \mathrm{mEq} / \mathrm{l}$. An intravenous infusion of $\mathrm{KCl}$ at $10 \mathrm{mEq} / \mathrm{hr}$ was initiated. The rhythm remained stable for 14 hours (Fig. 2, Strip 3) - phenytoin $100 \mathrm{mg}$ intravenously every 3 hours was continued for 48 hours. Subsequently the rhythm remained stable with only occasional ventricular

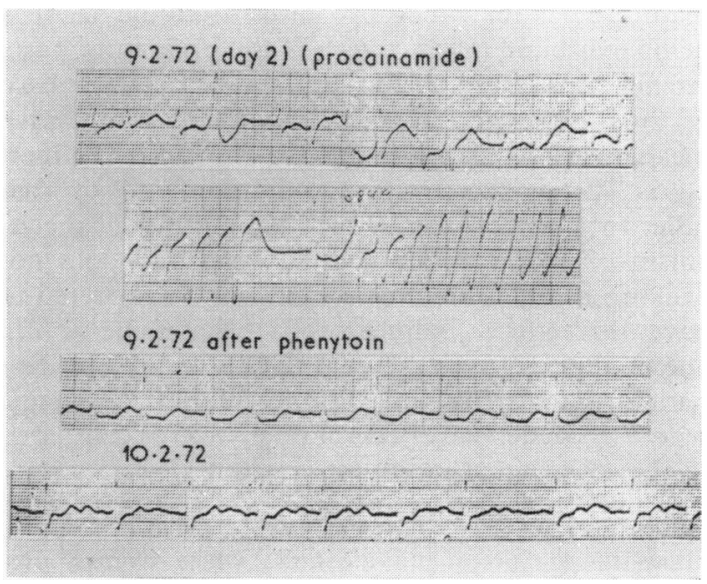

FIG. 2 Case 2. Representative electrocardiogram strips - details in text. 
premature beats. Thereafter the patient followed a fairly stable course with return of blood chemistries to normal.

\section{Discussion}

The effectiveness of phenytoin in suppressing ventricular arrhythmias is well established (Damato, 1969; Mercer and Osborne, 1967; Rosen, Lisak, and Ruben, 1967). Those occurring during anaesthesia, after cardioversion, and associated with digitalis intoxication are particularly responsive (Helfant, Scherlag, and Damato, 1967; Bashour et al., 1968). Eddy and Singh (1969) successfully abolished ventricular fibrillation previously unresponsive to intracardiac procainamide, propranolol, and direct current countershock in a 14-year-old girl after cardiac surgery with phenytoin; while Osborne (1964) suggested that phenytoin should be part of the routine drug armamentarium for the management of circulatory arrest. Despite this, little emphasis has appeared in the published reports on the effectiveness of phenytoin in the presence of hypokalaemia. This is the more remarkable as both procainamide and quinidine prolong the QT interval and so must aggravate the underlying defect which predisposes to arrhythmias when the serum potassium is low (Gettes et al., I962; Gettes and Surawicz, 1968; Pamintuan et al., 1970). Phenytoin, which has a different action at the cellular level and does not prolong the QT interval, seems an obvious choice in such a case (Pamintuan et al., 1970; Watanabe et al., 1963; Gettes, 1971).

Although both patients received potassium, which by itself may suppress arrhythmias (Reynolds, I965), this was not the mechanism of suppressing the arrhythmias (at least initially) in these two instances. The beneficial response occurred within 5 minutes of the administration of phenytoin in situations where lignocaine and procainamide had been ineffective. Rosen et al. (1967) had similar experiences with phenytoin in patients with hypokalaemia. This ability of phenytoin to suppress refractory ventricular arrhythmias in the presence of hypokalaemia and multiple electrolyte deficiencies is a valuable property, especially as the usual first line drug, lignocaine, is frequently ineffective in this setting (Vassalle, I97I).

Although phenytoin reduces sodium conductance in brain cells, it is not thought to have an identical effect on the myocardium. It does not prolong the repolarization process; on the contrary it tends to shorten the action potential and possibly enhance phase 4 prepotential (Gettes and Surawicz, I968; Gettes, 1971; Pamintuan et al., 1970). The shorter duration action potential and therefore relatively shortened refractory period will help prevent disorganization of the excitation front (Helfant et al.,
I967; Pamintuan et al., 1970; Gettes, I971). This will alleviate the underlying electrical defect which initially facilitated the repetitive mechanism by producing temporal dispersion of repolarization (Han et al., 1966; Han, 197I; Vassalle, 1971). As the QT interval and therefore the vulnerable phase is not prolonged into the period of occurrence of premature beats, even if the latter are not fully suppressed they will not tend to produce a repetitive mechanism (Palmer, 1962; Pick, 1964) - as can occur with the administration of quinidine (Gettes et al., 1962) and procainamide (Pamintuan et al., 1970).

As phenytoin is probably taken up by the fat depots, an initial loading dose of 3-5 $\mathrm{mg} / \mathrm{kg}$ may be required. This must be given slowly at a maximum rate of $50 \mathrm{mg}$ per minute (Damato, 1969). In the nonemergent situation the dose schedule suggested by Bigger, Schmidt, and Kutt (1968) may be used, consisting of increments of $100 \mathrm{mg}$ given at 5-minute intervals until the arrhythmia is abolished, until I $\mathbf{g}$ has been given, or until undesirable side effects appear. Constant monitoring of electrocardiogram is essential during this procedure.

Phenytoin is generally considered to be safe (Rosen et al., 1967; Damato, 1969), side effects being generally mild unless administration is too rapid, when bradycardia, hypotension, and transient atrioventricular block may occur (Karliner, 1967). Longterm side effects such as drowsiness, giddiness, and nystagmus are usually not experienced during the treatment of cardiac arrhythmias.

In closing we would like to emphasize the usefulness of phenytoin in the management of the notoriously resistant and malignant arrhythmias associated with hypokalaemia, where the usual antiarrhythmic agents are at the best ineffective and may even be dangerous. Indeed when hypokalaemia is suspected, phenytoin should probably be the initial drug of choice.

\section{References}

Bashour, F. A., Edmonson, R. E., Gupta, D. N., and Prati, R. (1968). Treatment of digitalis toxicity by diphenylhydantoin (Dilantin). Diseases of the Chest, 53, 263.

Bigger, J. T., Schmidt, D. H., and Kutt, H. (1968). Relationship between the plasma level of diphenylhydantoin sodium and its cardiac antiarrhythmic effects. Circulation, 38, 363 .

Damato, A. N. (1969). Diphenylhydantoin: pharmacological and clinical use. Progress in Cardiovascular Diseases, 12, 1.

Davidson, S., and Surawicz, R. (1966). Incidence of supraventricular and ventricular ectopic beats and rhythms and of atrioventricular conduction disturbances in patients with hypopotassemia (abstract). Circulation, 33, Suppl. 3, 85.

Eddy, J. D., and Singh, S. P. (1969). Treatment of cardiac arrhythmias with phenytoin. British Medical fournal, 4, 270. 
Gettes, L., and Surawicz, B. (1968). Effects of low and high concentrations of potassium on the simultaneously recorded Purkinje and ventricular action potentials of the perfused pig moderator band. Circulation, 23, 717.

Gettes, L. S. (1971). The electrophysiologic effects of antiarrhythmic drugs. American fournal of Cardiology, 28, 526.

Gettes, L. S., Surawicz, B., and Shiue, J. C. (1962). Effects of high $\mathrm{K}$, low $\mathrm{K}$, and quinidine on QRS duration and ventricular action potential. American fournal of Physiology, 203, II 35 .

Guyer, P. B. (1964). Stokes-Adams attacks precipitated by hypokalaemia. British Medical fournal, 11, 427.

Han, J. (1971). The concepts of reentrant activity responsible for ectopic rhythms. American Fournal of Cardiology, 28, 253.

Han, J., Millet, D., Chizzonitti, B., and Moe, G. K. (1966). Temporal dispersion of recovery of excitability in atrium and ventricle as a function of heart rate. American Heart fournal, 7r, 48I.

Helfant, R. H., Scherlag, B. J., and Damato, A. N. (1967). Electrophysiological properties of diphenylhydantoin sodium as compared to procaine amide in the normal and digitalis-intoxicated heart. Circulation, 36, 108.

Karliner, J. S. (1967). Intravenous diphenylhydantoin sodium (Dilantin) in cardiac arrhythmias. Diseases of the Chest, 51, 256.

Mercer, E. N., and Osborne, J. A. (1967). The current status of diphenylhydantoin in heart disease. Annals of Internal Medicine, 67, 1084

Osborne, J. A. (1964). Diphenylhydantoin in the treatment of clinical arrhythmias (abstract). American fournal of Cardiology, 13, 126.

Palmer, D. G. (1962). The interruption of T-waves by premature QRS complexes and the relationship of this phe- nomenon to ventricular fibrillation. American Heart fournal, 63, 367.

Pamintuan, J. C., Dreifus, L. S., and Watanabe, Y. (1970). Comparative mechanisms of anti-arrhythmic agents. American fournal of Cardiology, 26, 512.

Paulley, J. W. (1965). Hypokalaemia and cardiac arrest. Lancet, $\mathrm{I}, 2 \mathrm{18}$.

Pick, A. (1964). Manifestations of a vulnerable phase in the human heart. In Sudden Cardiac Death, p. 44. Ed. by B. Surawicz and E. D. Pellegrino. Grune and Stratton, New York.

Pick, A. (1966). Arrhythmias and potassium in man. American Heart fournal, 72, 295.

Reynolds, E. W. (1965). The use of potassium in the treatment of heart disease. American Heart fournal, 70, I.

Rosen, M., Lisak, R., and Rubin, I. L. (1967). Diphenylhydantoin in cardiac arrhythmias. American fournal of Cardiology, 20, 674 .

Sarma, R. N. (1965). Hypokalaemia and the electrocardiogram. Lancet, $\mathbf{1}, \mathrm{I} 220$.

Scherf, D., Cohen, J., and Shafiiha, H. (1967). Ectopic ventricular tachycardia, hypokalemia, and convulsions in alcoholics. Cardiologia, 50, 129

Swales, J. D. (1964). Hypokalaemia and the electrocardiogram. Lancet, 2, 1365 .

Vassalle, M. (1971). Automaticity and automatic rhythms. American fournal of Cardiology, 28, 245.

Watanabe, Y., Dreifus, L. S., and Likoff, W. (1963). Electrophysiologic antagonism and synergism of potassium and antiarrhythmic agents. American fournal of Cardiology, 12 , 702.

Requests for reprints to Dr. Michael O'Reilly, County Hospital, Tullamore, Offaly, Ireland. 